Dhaka Univ. J. Biol. Sci. 28(1): 49-59, 2019 (January)

\title{
RELATIONSHIP BETWEEN PARENTING STYLES AND DEPRESSION IN ADOLESCENTS
}

\author{
Sanchary Prativa and Farah Deeba* \\ Department of Clinical Psychology, University of Dhaka, Dhaka-1000, Bangladesh
}

Key words: Parenting style, Depression, Adolescent

\begin{abstract}
This study aimed at examining the relationship between parenting styles and depression in adolescents. Convenient sampling was used to collect 100 adolescents (Mean age $=15.25$ years, $\mathrm{Sd}=0.90$ ) from two colleges of Dhaka city, Bangladesh. Parental Attitude Questionnaire (PAQ) was used to measure parenting styles and two other self-report measures, Hospital Anxiety and Depression Scale (HADS) and Short Mood and Feelings Questionnaire (SMFQ) were used to assess depression in adolescents. From multiple regression analysis significant relationship was found between parenting style and adolescents' depression measured by one self-rating scale. The overall regression model for investigating the relationship between parenting style and depression in adolescent was significant with HADS, $(F=3.77, \mathrm{p}=0.007)$ but not significant with SMFQ scores $(\mathrm{F}=0.880, \mathrm{p}=0.454)$. For the dependent variable of depression measured by HADS, the strongest predictors were authoritative parenting style $(\beta=-0.28, p=0.03)$ and monthly income of the family which is also significant $(\beta=0.25, p=0.01)$. Implications of the findings for child rearing and research are discussed.
\end{abstract}

\section{Introduction}

Parenting styles have been described as the collection of parental behaviors that can made an environment of parent-child interactions across situations ${ }^{(1)}$. Based on the work of Baumrind several broad typologies of parenting styles such as authoritative, authoritarian and permissive have been identified ${ }^{(2-4)}$. These styles tend to differ along the dimensions of warmth and control. Warmth refers to the degree in which parents display involvement, responsiveness, and support to their children ${ }^{(5)}$. Warm and supportive parenting involve behaviors that are physically and emotionally affectionate, approving, loving and caring(6). Parental warmth, expressed in both physical and verbal ways has been found to be a universal phenomenon(7). Control includes the demands or expectations parents place upon or hold for their children and the degree of monitoring present in parenting(7). To Baumrind, these were choices between two extremes.

Authoritative parents tend to display both high control and high responsiveness and warmth to their children. In such relationship expectations are clearly stated, rules are

*Author for correspondence: <farahdeeba@du.ac.bd>. 
firm and rational, and discipline is administered in a consistent manner. This parenting style offers a balance between high nurturance and high control, in addition to clear communication about expectations for the child(2). According to Baumrind authoritarian parenting is restrictive and punitive, and places firm limits and controls on children with little or no verbal exchange. Authoritarian parenting in contrast is associated with a myriad of negative outcomes throughout development ${ }^{(8)}$.In permissive parenting, few or no rules and little or no controls are exerted over the children. Children under such parenting style are given complete freedom to make their life decisions and behave autonomously and independently(4). This type of parenting style was associated with social incompetence and lack of self control(9). Permissive parents exhibit high levels of warmth and low levels of control. Because warmth is displayed through overindulgence, permissive parents tend to be non-demanding and avoidant of controlling behavior or outlining boundaries in the children's environment ${ }^{(10)}$. The overall idea of permissive parenting is to allow the child extensive autonomy, corroborated by high parental support, in the hopes of anything of child's maturity and responsibility, is inconsistent and confusing ${ }^{(7)}$. These parents often surrender to the demands of their child. Bad behavior of the child is seldom acknowledged or corrected by parents and rules are either not enforced or are not clearly communicated. According to Baumrind children of permissive parents are often left to regulate their own activities, behavior, and emotions at a young age ${ }^{(2)}$.

Parenting is a complex activity that includes many specific behaviors that work individually and together to influence child outcomes In the 1960s, Baumrind was interested in the different ways that parents attempted to control or socialize their kids. She noted that the very idea of parental control-of adults acting as authority figures-had fallen into controversy. Maybe that is because people were equating "control" with blind obedience, harsh punishments, and domineering, manipulative behavior ${ }^{(11)}$. Some other studiesfound significant associations between parenting style and depression. It is found that positive correlation exists between authoritarian parenting style and depression ${ }^{(12,13)}$.

Human beings change and develop most dramatically during adolescence in the life cycle. Various biological, cognitive, emotional, and social changes that take placein adolescence and the parent-child relationship get affected by parenting styles ${ }^{(4,5)}$.Many studies have shown a link between parent-child interaction and emotional and behavioral adjustment in early childhood, middle childhood, and adolescence ${ }^{(14)}$. Therefore, it seems necessary to clarify which factors influence parenting styles in this particular period of life.

Beginning in early childhood, authoritative style of parenting has been shown to produce higher levels of social competence ${ }^{(3)}$ a greater ability to regulate emotions, high social skills and self-regulation(10). Adolescents of authoritative parents have higher self esteem, are socially confident and competent ${ }^{(3)}$ are self-reliant, have greater respect for 
their parents, display increased academic performance, possess higher levels of selfesteem, engage in fewer acts of deviant behavior and more pro-social behavior ${ }^{(15)}$.

As originally conceptualized by Baumrind parenting typologies consist of authoritative, permissive, and authoritarian parenting styles, which affect the overall behavior of the child. Magnusse ${ }^{(16)}$ found that both adolescents and parental over-control are associated with higher levels of depressive symptoms. Some other studies found significant associations between parenting style and depression ${ }^{(12-14)}$. It is found that positive correlation exists between authoritarian parenting style and depression. Depression is one of the most widespread mental disorders among adolescent's population, second only to alcohol abuse in Western society and the scenario is not so bright in Asian societies ${ }^{(17) .}$ Depression is an affective, or mood disorder. It is an illness that immerse its sufferers in a world of self-blame, confusion and hopelessness. It is an illness of the mind and the body. Depression in adolescents has been acknowledged as a problem ${ }^{(14)}$. Depression is the main problem faced by the mental health professionals as an independent disease and it is a major associated factor in other problems like suicide, substances abuse and common cause of school failure and school dropout among adolescent ${ }^{(17) . .}$ In our country there is a scarcity of research findings on whether parenting style has any relationship with emotional problems of children especially of adolescents. Thus, the main purpose of the present study is to examine the relationship of depression with parenting style among adolescents.

\section{Materials and Methods}

Purposive sampling was used to collect the sample for this study comprised of 100 adolescents (girls $=53$ and boys $=47$ ) drawn from two different colleges of Dhaka city.Some similar types of schools in Dhaka city were approached for conducting the research and only two gave permission to work. Students were contacted in their respective classes through their class teachers. The students age ranged from 14 to 18 years (Mean age $=15.25$ year; $\mathrm{Sd}=0.90$; Girls' Mean age $=15.36$ years, $\mathrm{Sd}=0.87$; Boys Mean age $=15.15$ years, $\mathrm{Sd}=0.93$ ). Among them 86 were muslims, 10 hindus, one buddhuist and three christians. Monthly income of their families were mostly $20-70$ thousand BDT per month $(N=70)$, next highest group was with 20 thousand and below $(\mathrm{N}=16)$ and finally 70 thousand and above $(\mathrm{N}=14)$ respectively. Most of the families were nuclear type $(\mathrm{N}=82)$, then joint type $(\mathrm{N}=13)$ and then only father and child $(\mathrm{N}=3)$ and only mother and child $(\mathrm{N}=2)$. Most of the mothers of the children were housewives $(\mathrm{N}=76)$ and some different types of works (job, $\mathrm{N}=21$; business, $\mathrm{N}=2$ and others, $\mathrm{N}=1$ ). Fathers were mostly government officials $(\mathrm{N}=55)$. And others were businessman $(\mathrm{N}=$ $22)$, non-government organizations' employees $(\mathrm{N}=21)$ and other occupants $(N=2)$. Numbers of siblings ranged from none to 4 for our sample (no siblings, $\mathrm{N}=5$; one sibling, $\mathrm{N}=21 ; 2$ siblings, $\mathrm{N}=40 ; 3$ siblings, $\mathrm{N}=28$ and 4 siblings, $\mathrm{N}=6$ ). Most of the children in 
the sample were first born $(\mathrm{N}=43)$, then second born $(\mathrm{N}=42)$, third born $(\mathrm{N}=12)$, fourth born and fifth born. All these demographic variables are given in the Table 1 according to the gender of the participants.

For data collection, present study used the following instruments.

Demographic and personal information questionnaire: By this questionnaire, the data on age, sex, monthly family income, mothers' and fathers' occupation, family type, number of siblings and birth order were collected.

The Parental Authority Questionnaire (PAQ): The PAQ originally developed by Buri(19) is a 30-item questionnaire that measures different parenting styles, that are authoritative, authoritarian and permissive. It is a 5-point Likert type scale ranging from 1 (disagree) to 5 (agree) and the information are to be given by the child of a parent(s).The internal consistency (Cronbach's $\alpha$ ) of the English version PAQ ranges from 0.74 to 0.87 and the test-retest reliabilities range from 0.77 to $0.87^{(19)}$. The Bangla version of the scale has good content validity. The split-half reliability of the Bangla version of the full PAQ was found to be $0.72^{(14)}$. Cronbach $\alpha$ for the subscales and full scale of PAQ were found ranged from good to satisfactory with our adolescent sample (permissive $=0.43$, authoritarian $=0.60$, authoritative $=0.67$ and full scale $=0.85$ ),

The Short Mood and Feelings Questionnaire (SMFQ): It was developed by Angold et al.(20). It is an 13-item short scale from a longer 33-item questionnaire (the original MFQ). The child must rate whether the provided phrase is indicative of their feelings and actions on three options ("Not True", "Sometimes", or "True") over the time frame of the previous two weeks. Each item is rated on a 3-point Likert scale with values of 0 - 2 assigned to response statements of "True" (0), "Sometimes" (1), and "Not True" (2) given a timeframe over the previous two weeks. The internal reliability coefficient for the survey has been found to be good (Cronbach's alpha=0.85), suggesting that this shortened version of the survey adapted from the long version is sufficient. Cronbach's alpha of the Bangla version to this scale was strong at 0.80 found with Bangladeshi children and adolescents in a nationwide stusy ${ }^{(21)}$. Similar internal consistency was found with our adolescent participants too in current study (Cronbach $\alpha=0.813$ ).

The Hospital Anxiety and Depression Scale (HADS): It was originally developed by Zigmond and Snaith ${ }^{(22)}$ and is commonly used by doctors to determine the levels of anxiety and depression that a client is experiencing. The HADS is a 14-item scale that generates ordinal data. Seven of the items relate to anxiety and seven relate to depression. One can score in between 0 - 21 one a three point Likert-scale rating for both sub-scales. Cut-off score 8 and above are found to be indicative of depression and anxiety for adults(23). The measure was found to have satisfactory level of reliability and valid when administered with adolescents(24). The correlation co-efficient of the Bengali translation of HADS was found 0.76 for anxiety sub scale and 0.94 for depression subscale, with stroke patients ${ }^{(25)}$. The measure was used as anxiety may be strongly 
comorbid with depression in adolescents ${ }^{26,27)}$. The internal consistency for HADS total (Cronbach $\alpha=0.673$ ), depression (Cronbach $\alpha=0.575$ ) and anxiety (Cronbach $\alpha=0.622$ ) subscale of HADS were found good with our sample.

Standard data collection procedure was followed to collect data from the participants. After getting written consent from the participants and their parents the paper-based survey was administered to the participants in a classroom of the respective college. Participants were assured of voluntary participation and that all collected data would be kept confidential. Participants were informed that they could withdraw from the study at any time. After that the test tools were administered with the participants. These tests were also administered following the instructions specified in the respective test manuals. The general testing conditions were satisfactory and the procedure was uniform all through. All the tests were scored as per the procedure described in respective test manual.

\section{Results and Discussion}

Multiple regression analysis was carried out to examine the relationship between major variables such as parenting styles (authoritative, authoritarian and permissive) and depression. For this purpose, data were analyzed in multiple regression using three parenting styles as predictors, and depression as dependent variable. Before this analysis, the major assumptions of multiple regressions such as assumption of linearity, assumption of multicollinearity, homoscedasticity and independence of observation were tested. The linearity was tested by graph, the multicolinearity was approximated by coefficients, homoscedasticity was tested by scatterplots and independence of observation were assessed by model summary box. To investigate the association between parenting styles and depression in adolescents, data were analyzed in multiple regression using parenting styles as a predictor and depression in adolescents as dependent variable. Correlations of the variables were also calculated to find out the relationships among variables.

Correlations have been found in different demographic variables and parenting styles (independent variables) measured by $\mathrm{PAQ}^{*}$. Significant positive correlations were found in age and authoritarian parenting style $(\mathrm{r}=0.23, \mathrm{p}<0.05)$, monthly family income and father's occupation $(r=0.29, \mathrm{p}<0.01)$, family type with both mother's $(\mathrm{r}=0.48$, $\mathrm{p}<0.01)$ and father's occupation $(\mathrm{r}=0.23, \mathrm{p}<0.05)$, birth order with number of siblings $(\mathrm{r}=0.52, \mathrm{p}<0.01)$ and authoritative parenting style $(\mathrm{r}=0.25, \mathrm{p}<0.05)$. Negative correlation was found between monthly family income and authoritative parenting style $(\mathrm{r}=-0.20, \mathrm{p}<0.05)$. The only demographic variable monthly income of the family correlates with depression score of HADS $(r=0.29, \mathrm{p}<0.01)$. Correlation among the

*The table for correlation coefficient parameters in between different demographic variables and parenting styles measured by PAQ can be obtained from corresponding author on request. 
scores of SMFQ $($ Mean $=10.03, \mathrm{SD}=5.26)$, subscales of depression $(\mathrm{M}=8.55, \mathrm{Sd}=$ $3.41)$, anxiety $(M=9.90, S d=3.80)$ of HADS, and HADS full scale $(M=18.45, S d=5.97)$, and were found all positively correlated and significant at 0.01 level. However, correlation with SMFQ and HADS scores and PAQ scores were not significant for all cases except two sub-scales PAQ (authoritative parenting style) and HADS (Depression), which were negatively correlated to each other. Correlation coefficients are given in Table 1.

Table 1. Correlation coefficients of measures of parenting style and emotional states of adolescents.

\begin{tabular}{lllllll}
\hline Scales & SMFQ & 1 & 2 & 3 & 4 & 5 \\
\hline 1. HADS (Depression) & $0.350^{* *}$ & & & & & \\
2. HADS (Anxiety) & $0.426^{* *}$ & $0.353^{* *}$ & & & & \\
3. HADS (Total) & $0.474^{* *}$ & $0.800^{* *}$ & $0.844^{* *}$ & & & \\
4. PAQ (Permissiveness) & -0.053 & -0.065 & -0.109 & -0.107 & & \\
5. PAQ (Authoritarian) & 0.040 & 0.035 & 0.003 & 0.022 & $0.325^{* *}$ & \\
6. PAQ (Authoritative) & -0.110 & $-0.208^{*}$ & -0.043 & -0.147 & $0.467^{* *}$ & $0.548^{* *}$ \\
\hline
\end{tabular}

${ }^{*}$ Correlation is significant at the 0.05 level. ${ }^{* *}$ Correlation is significant at the 0.01 level.

The primary purpose of the present study was to investigate whether depression in adolescents varies as a function of parenting style(s). We examined this by keeping monthly income in the model with three different parenting styles as measured by PAQ. Results are presented by the measures used in the study.

The model with the predictors for depression measured by SMFQ was not significant $[F(4,95)=0.896, p=0.496]$. Beta values of the predictors for SMFQ are given in Table 2 .

Table 2. Regression of depression measured by SMFQ on permissive parenting, authoritative parenting, authoritarian parenting and monthly family income.

\begin{tabular}{|c|c|c|c|c|c|}
\hline \multirow{2}{*}{ Model } & \multicolumn{2}{|c|}{ Unstandardized coefficients } & \multirow{2}{*}{$\begin{array}{c}\text { Standardized } \\
\text { coefficients } \\
\text { Beta }\end{array}$} & \multirow{2}{*}{$T$} & \multirow{2}{*}{ Sig. } \\
\hline & $B$ & Std. error & & & \\
\hline \multirow{3}{*}{ Authoritarian } & -0.014 & 0.096 & -0.016 & -0.143 & 0.227 \\
\hline & 0.109 & 0.094 & -0.140 & 1.161 & 0.249 \\
\hline & -0.104 & 0.085 & -0.160 & -1.216 & 0.887 \\
\hline Monthly income & 0.958 & 0.984 & 0.100 & 0.973 & 0.333 \\
\hline
\end{tabular}


Interestingly overall predictors could account for $13.7 \%$ variance for depression as measured by HADS and the model was significant $[F(4,95)=3.765, \mathrm{p}=0.007]$. Beta values of the predictors for HADS are given in Table 3.

Table 3. Regression of depression measured by HADS on permissive parenting, authoritative parenting, authoritarian parenting and monthly family income.

\begin{tabular}{|c|c|c|c|c|c|c|}
\hline \multirow{2}{*}{\multicolumn{2}{|c|}{ Model }} & \multicolumn{2}{|c|}{ Unstandardized coefficients } & \multirow{2}{*}{$\begin{array}{c}\begin{array}{c}\text { Standardized } \\
\text { coefficients }\end{array} \\
\text { Beta }\end{array}$} & \multirow[t]{2}{*}{$T$} & \multirow[t]{2}{*}{ Sig. } \\
\hline & & $\mathrm{B}$ & Std. Error & & & \\
\hline \multirow{4}{*}{1} & Permissive & 0.010 & 0.059 & 0.018 & 0.165 & 0.870 \\
\hline & Authoritative & -0.115 & 0.052 & -0.275 & -2.207 & 0.030 \\
\hline & Authoritarian & 0.100 & 0.058 & 0.199 & 1.739 & 0.085 \\
\hline & Monthly income & 1.57 & 0.609 & 0.254 & 2.605 & 0.011 \\
\hline
\end{tabular}

It is interesting that here authoritative parenting style was found negatively related and monthly income of the family was positively related with the children depression.

We ran the regression model with predictors for anxiety measured by HADS as well and it was not significant $[F(4,95)=0.336, p=0.853]$. Beta values of the predictors for anxiety score on HADS are presented in Table 4.

Table 4. Regression of anxiety measured by HADS on permissive parenting, authoritative parenting, authoritarian parenting and monthly family income.

\begin{tabular}{|c|c|c|c|c|c|c|}
\hline \multirow{2}{*}{\multicolumn{2}{|c|}{ Model }} & \multicolumn{3}{|c|}{ Unstandardized coefficients Standardized coefficients } & \multirow[t]{2}{*}{$T$} & \multirow[t]{2}{*}{ Sig. } \\
\hline & & B & Std. Error & Beta & & \\
\hline \multirow{4}{*}{1} & Permissive & -0.072 & 0.070 & -0.118 & -1.022 & 0.309 \\
\hline & Authoritative & -0.008 & 0.062 & -0.018 & -0.135 & 0.893 \\
\hline & Authoritarian & 0.028 & 0.069 & -0.050 & -0.410 & 0.682 \\
\hline & Monthly income & -0.099 & 0.720 & -0.014 & -0.138 & 0.891 \\
\hline
\end{tabular}

Kantrowitz and Wingert ${ }^{(28)}$ noted that today's teens are richer, more educated and healthier than ever before and yet there seems to be an overwhelming rise of serious emotional problems in this population. The immense pressure and responsibility brought on by juggling work, extra curricular activities, homework, social life, and other events going on in the home such as divorce of parents, parenting style, abuse or neglect can only increase the likelihood of attracting some form of emotional impairment ${ }^{(13,14,28)}$. Our findings resonate the similar facts that are existent in the lives of adolescents of Dhaka city. 
As per Baumrind(4), authoritarian parents imposes high control and lower levels of warmth upon their children, therefore this style allows minimal freedom for the child in decisions making. Further, in this form of one-way communication, the child is not permitted to express views or opinions. They have very strict rules for their children that they expect to follow unconditionally. These parents often utilize punishment, but are not willing or able to explain the reasoning behind their rules ${ }^{(3)}$. They have affection for their children but lack in understanding of how their actions shape their child development ${ }^{(2)}$. Thus, authoritarian parenting encourage compliance, not communication and it may encourage untruthful communication. As a result, children of these parents may not develop good communication skills and not feel free to share anything with their parents ${ }^{(2,3)}$.

We have found that the authoritative parenting style has a negative correlation with depression. As we had mentioned earlier that authoritative parents tend to display both high control and high responsiveness and warmth to their children ${ }^{(2,3)}$, therefore this parenting style offers a balance between high nurturance and high control, in addition to clear communication about expectations for the child ${ }^{(4,10,11)}$. Authoritative parenting is a two-way interaction between parents and a child. This style is based on mutual respect between parents and children. Families, which use this style, set a number of rules that are vital for all family members. Children are supposed to follow these rules because the rules were discussed, understand, agreed and therefore children are not in fear of their parents. This style of parenting helps the child become an independent and responsible person. The child knows exactly what he allowed to do and what he is not supposed to. It reasoned that children of authoritative parents tends to develop better cognitiveemotional functioning on their children ${ }^{(16)}$. Also, in permissive parenting, children mostly take over the controlling of family rules; therefore, the level of stress is not much in their own life $(2,3,14)$. However, this is not very helpful for mental health since discipline and lifestyle of such children usually do not remain in healthy ways leaving them susceptible to other mental health problems, which is beyond this paper's capacity to discuss.

Most interesting finding of the study is that high monthly family income is not related to depression. This is a significant finding for child rearing practice. Many of the times it is assumed that higher income may led to better mental health of the family members, however, present findings clearly states that high economical condition cannot ensure better mental health, which is supported by the previous findings $(30,31)$. We have found strong negative relationship with family income and authoritative parenting and very strong relationship between family income and father's occupation. These findings suggest the possibility that once the fathers are earning higher then they either become permissive or authoritarian. These imply the importance of fathers' authoritative presence in the lives of children. Different other studies have found and emphasized similar notions as well ${ }^{(32)}$. 
This study has some limitations. First, it was conducted with small number of participants. Secondly, the sample was taken from only two colleges. Thirdly, scores obtained through the Bengali version of HADS was not checked with Bangladeshi children. This makes it difficult to assure how much of these findings can be generalized to the completely adolescent population of the country. Due to shortage of time and other relevant supports (e.g. fund, access, etc.), data were collected from Dhaka city only. Thus, it cannot be claimed that the sample was representative. Further, the study could not control some of the extraneous variable like socioeconomic condition, number of siblings, family type and others that could affect the result of the study. However, the findings of the present study are important for clinical implications and further research. Therefore, in future a large survey may be conducted with a large number of participants from different areas of Bangladesh.

\section{References}

1. Mize J and GS Pettit 1997. Mothers social coaching, mother-child relationship style, and children's peer competence: Is the medium the message? Child Development 68(2): 312-332.

2. Baumrind D 1967. Child care practice anteceding three patterns of preschool behavior, Genetic Psychology Monographs 75(1): 43-88.

3. Baumrind D 1978. Reciprocal rights and responsibilities in parent-child relations. Journal of Social Issues 34(2): 179-196.

4. Baumrind D1991.The influence of parenting style on adolescent competence and substance use. Journal of Early Adolescence, pp. 56-95.

5. Hart CH, LB Newell and SF Olsen 2003. Parenting skills and social-communicative competence in childhood. In: J. O. Greene and B. R. Burleson (Eds.), Handbook of communication and social interactionskills, pp. 753-797.

6. Openshaw DK, DL Thomas and BC Rollins 1984. Parental influences of adolescent self-esteem. Journal of Early Adolescence 4(3): 259-274.

7. Rohner RP, 1986. The warmth Dimension. London: Sage.

8. Peterson GW and D Hann, 1999. Socializing children and parents in families. In M. B. Sussman, SK Steinmertz, and GW Peterson (Eds.), Handbook of Marriage and Family, (2nd Ed.), pp 27.

9. Maccoby EE and JA Martin 1983. Socialization in the context of the family: Parent-child interaction. In: PH Mussen (ed) and EM Hetherington (vol. ed.), Handbook of child psychology: Vol. 4. Socialization, personality, and social development (4th ed., pp. 1-101).

10. Baumrind D and AE Black 1967. Socialization practices associated with dimensions of competence in preschool boys and girls. pp. 291-327.

11. Baumrind D 1966. Effects of Authoritative Parental Control on Child Behavior, Child Development 37(4): 887-907.

12. Ayuazian J 1996. Parenting styles in the American family. Int. Sec. (A). Humanities \& Social Science. pp. 1010

13. Pinquart, M 2017. Associations of parenting dimensions and styles with internalizing symptoms in children and adolescents: A meta-analysis. Marriage \& Family Review 53(7): 613-640. doi:10.1080 01494929.2016.1247761. 
14. Karim AKMR, T Sharafat and AY Mahmud 2013. Cognitive emotion regulation inchildren as related to their parenting style, family type and gender. Journal of Asiatic Society Bangladesh 39(2): 211-220.

15. Dornbusch, SM, PL Ritter, PH Leiderman, DF Roberts and MJ Fraleigh 1987. The relation of parenting style to adolescent performance. Child development pp. 1244-1257.

16. Magnussen MG 1991. Characteristics of depressed and non-depressed children and their parents. Child psychiatry and human development 21(3): 185-191.

17. Kringlen E, S Trgerson, and V Cramer 2001. A Norweigian Psychiatric epidemiological study, American Journal of Psychiatry 158: 1091-1098.

18. Birmaher B, ND Ryan DE Williamson, DA Brent, JDaufman, RE Dahl JPerel, and B Nelson, 1996. Child and Adolescent Psychiatry 35: 427-1439.

19. Buri J R 1991. Parental authority questionnaire. Journal of Personality \& Social Assessment. 57(1): 110-119, DOI: $10.1207 /$ 15327752jpa5701_13

20. Angold A, EJ Costello, SC Messer, A Pickles, F Winder and D Silver 1995. The development of a short questionnaire for use in epidemiological studies of depression in children and adolescents. International Journal of Methods in Psychiatric Research 5: 237- 249.

21. Deeba F, RM Rapee and T Prvan 2015. Psychometric properties of two measures of childhood internalizing problems in a Bangladeshi sample. Br. J. Clin. Psychol. 54: 214-232. doi:10.1111/bjc.12071

22. Zigmond AS and RP Snaith 1983. The Hospital Anxiety and Depression Scale. Acta Psychiatrica scandinavica 67(6): 361-370.doi:10.1111\}.1600- 0447.1983.tb09716.x

23. Bjelland, I AA Dahl, TT Haug and D Neckelmann 2002. The validity of the Hospital Anxiety and Depression Scale. An updated literature review. Journal of Psychosomatic Research 52(2): 69-77. doi:10.1016/\$0022-3999(01)00296-3.

24. White D, C Leach, R Sims, M Atkinson and D Cottrell 1999. Validation of the Hospital Anxiety and Depression Scale for use with adolescents. Br. J. Psychiatry 175: 452-454.

25. Chowdhury KU 1996. Emotional reactions to stroke - A pilot study in Dhaka city Department of Clinical Psychology, University of Dhaka, (Unpublished thesis).

26. Garber J and VR Weersing 2010. Comorbidity of Anxiety and Depression in Youth: Implications for Treatment and Prevention. Clinical Psychology: A Publication of the Division of Clinical Psychology of the American Psychological Association 17(4): 293-306. http://doi.org/10.1111/14.1468-2850.2010.01221.x

27. Cummings CM, NE Caporino and PC Kendall 2014. Comorbidity of anxiety and depression in children and adolescents: 20 Years After. Psychological Bulletin 14(3): 816-845. http://doi.org/10.1037/a0034733

28. Kantrowitz B and P Wingert 2008. How well do you know your kid? Newsweek. Retrieved Apri114, 2008, from: www.newsweekcomlid/88250/output/print14.

29. Hock RS, T Mendelson, PJ Surkan, JK Bass, CP Bradshaw and MJ Hindin 2018. Parenting styles and emerging adult depressive symptoms in Cebu, the Philippines. Transcultural Psychiatry 55(2): 242-260. doi:10.1177/1363461517748813

30. Scaramella IV and LD Leve 2004. Clarifying parent-child reciprocities during early childhood: The early childhood coercion model. Clinical Child and Family Psychology Review, pp. 89-107. 
31. Lin H, T TangJ Yen, C Ko, C Huang, S Liu and C Yen 2008, Depression and its association with self-esteem, family, peer and school factors in a population of 9586 adolescents in southern Taiwan. Psychiatry and Clinical Neurosciences 62: 412-420. doi:10.1111ð.14401819.2008.01820.x

32. Coley RL 2003. Daughter-father relationships and adolescent psychosocial functioning in low-income African American Families. Journal of Marriage and Family 65: 867-875. doi:10.1111 ’.1741-3737.2003.00867.x

(Manuscript received on 27 July, 2017; revised on 8 October, 2018) 